\title{
AVALIAÇÃO DA ALIMENTAÇÃO EM CRIANÇAS COM FISSURA DE LÁBIO E/OU PALATO ATENDIDAS EM UM HOSPITAL DE PORTO ALEGRE
}

\section{Evaluation of feeding in children with cleft lip and/or palate assisted in a hospital of Porto Alegre}

\author{
Paloma Letelier Campillay (1), Susana Elena Delgado ${ }^{(2)}$, Silvana Maria Brescovici ${ }^{(3)}$
}

\begin{abstract}
RESUMO
Objetivo: avaliar a alimentação de crianças fissuradas e descrever suas características; verificar o tipo de alimentação e suas dificuldades alimentares. Métodos: foi um estudo quantitativo, transversal, observacional e descritivo. Participaram 23 pacientes fissurados de zero a nove anos, que realizaram avaliação do sistema estomatognático e cujos responsáveis foram entrevistados. Realizou-se análise estatística descritiva dos dados obtidos na avaliação, assim como análise teórica. Resultados: 0 tipo de fissura mais encontrada foi a Fissura Transforame Unilateral. Das 23 crianças, duas $(8,75 \%)$ foram amamentadas exclusivamente. As maiores dificuldades alimentares foram: seis $(26,1 \%)$ dificuldade para sugar, $10(43,5 \%)$ engasgos, quatro $(17,4 \%)$ dificuldade para deglutir, três $(13,0 \%)$ dificuldade para mastigar e $12(52,2 \%)$ tinham refluxo nasal. As alterações das funções do Sistema Estomatognático mais frequentes foram a interposição lingual importante na deglutição e mastigação do tipo mascagem. Conclusão: a fissura transforame, mesmo sendo mais complexa, não excluiu o aleitamento materno exclusivo; o tipo de alimentação relacionado com a idade dos pacientes apresenta-se de maneira adequada; boa parte dos pacientes ainda usa a mamadeira com bico comum, constituindo um hábito deletério. As maiores dificuldades na alimentação relatadas pelas mães foram engasgos, refluxo nasal e dificuldade de sugar. As crianças que não apresentaram queixas de dificuldade de alimentação eram portadoras, na sua maioria, de fissura pré-forame incisivo.
\end{abstract}

DESCRITORES: Fissura Labial; Fissura Palatina; Métodos de Alimentação; Transtornos da Alimentação

\section{INTRODUÇÃO}

As fissuras labiais ou labiopalatinas são um conjunto de anormalidades na formação da face, que incluem uma grande variedade de lesões, desde as mais simples como a fissura de lábio até as mais complexas como a fissura completa de lábio e

(1) Fonoaudióloga; Clínica Paloma Campillay, RS.

(2) Fonoaudióloga; Professora Adjunta do Curso de Fonoaudiologia da Universidade Luterana do Brasil, ULBRA, Canos, RS; Especialista em Motricidade Oral; Mestre em Saúde Coletiva pela Universidade Luterana do Brasil.

(3) Fonoaudióloga; Professora Adjunta do Curso de Fonoaudiologia da Universidade Luterana do Brasil, ULBRA, Canos, RS; Especialista em Motricidade Oral; Mestre em Medicina: Ciências Médicas pela Universidade Federal do Rio Grande do Sul.

Conflito de interesses: inexistente palato. Apesar das fissuras labiopalatinas por si só não serem uma condição que compromete a vida do recém-nascido, a deformação na face e a dificuldade para ingerir alimentos criam nos pais uma grande preocupação ${ }^{1-3}$.

A etiologia depende de fatores ambientais e genéticos, podendo ocorrer isoladamente ou em associação. Os fatores ambientais são os nutricionais, tóxicos, infecciosos, o uso de medicamentos, radiações ionizantes, estresse e tabagismo materno, durante o período de formação do bebê. Acredita-se, ainda, na influência de fatores genéticos, pois mais da metade dos sujeitos com fissuras apresenta familiares portadores dessa mesma alteração ${ }^{1,2}$.

No Brasil, de acordo com o Centro de Atendimento Integral ao Fissurado Lábio-Palatal, apesar de não se ter muito investimento em pesquisas para 
atualização dos dados, pode-se afirmar que, para cada 1.000 nascimentos, duas crianças apresentam fissura labiopalatina, sendo a mortalidade, no primeiro ano de vida, em torno de $30 \%{ }^{4}$.

A alimentação do fissurado labiopalatino é, na maioria das vezes, muito difícil, ainda mais se a família não foi orientada. Os problemas mais comuns são sucção inadequada por falta de pressão intraoral; tempo de mamada prolongada e regurgitação ${ }^{3}$. Crianças com fissura pré-forame incisivo podem não ter problemas alimentares, mas aquelas com fissuras pós-forame ou transforame incisivo podem apresentar dificuldades, por não conseguirem uma pressão intra-oral adequada ${ }^{3-5}$. A sucção insuficiente, vômitos e engasgos acontecem quando as mães são orientadas inadequadamente quanto ao melhor método de alimentar o recém-nascido fissurado. Uma criança portadora de fissura labiopalatina tem condições de movimentar a mandíbula ao sugar o peito, apesar da pouca pressão intra-oral, quando não apresentar outras alterações congênitas associadas à fissura ${ }^{2,5}$. A alimentação oral deve ser estimulada precocemente, ou seja, logo após o nascimento, acompanhada por nutricionistas, enfermeiras, neonatologistas, fonoaudiólogos, e outros membros da equipe; esses cuidados vêm aumentar as chances de sucesso, de se alcançar melhores condições possíveis de vida, possibilitando que, mais brevemente, as interações corretivas sejam realizadas com êxito, evitando futuras complicações ${ }^{2,4,5}$. Os métodos de alimentação necessários para o recém-nascido fissurado são basicamente os mesmos adotados para outros recém-nascidos normais. A criança com fissura labiopalatina tem o sistema nervoso íntegro e apresenta funções e potencial de crescimento dentro da normalidade, o que é exceção para algumas síndromes ou quando a fissura vem acompanhada de outra deformidade ${ }^{4}$.

O fonoaudiólogo deve identificar os hábitos alimentares, como o uso prolongado de mamadeira, para detectar possíveis dificuldades no desenvolvimento da alimentação de transição. Geralmente, esses pacientes preferem alimentos mais pastosos e umidificados para deglutição mais fácil e sem muito esforço na mastigação. Além disso, eles podem apresentar problemas oclusais que acabam interferindo na mastigação e alterando também a fala ${ }^{2,3}$.

Considerando que o crescimento durante os primeiros anos de vida é rápido, a infância é um dos períodos mais críticos do ciclo de vida; que a alimentação e nutrição são essenciais para que essas crianças desenvolvam-se adequadamente e que, segundo alguns estudos, a falta de orientações adequadas sobre as particularidades alimentares de cada criança fissurada torna muitas vezes a alimentação um problema, justifica-se a investigação aprofundada das características de alimentação das crianças portadoras de fissura, com o intuito de traçar melhores e mais eficientes estratégias para garantir uma alimentação segura e saudável.

Portanto, este trabalho visa avaliar a alimentação de crianças fissuradas e descrever suas características; verificar o tipo de alimentação dos portadores de fissuras, as alterações do sistema estomatognático e suas dificuldades alimentares.

\section{MÉTODOS}

Foi feito um estudo quantitativo, do tipo transversal, observacional e descritivo.

Participaram desta pesquisa 23 pacientes fissurados que frequentavam o Ambulatório de Cirurgia Pediátrica do Hospital da Criança Conceição (GHC), situada na cidade de Porto Alegre/RS.

A amostra foi não-probabilística e de conveniência. Teve como critério de inclusão crianças de zero a nove anos de idade, de ambos os sexos, portadoras de fissuras labiais e/ou labiopalatinas, com cirurgias primárias realizadas ou não. Como critério de exclusão, os sujeitos com síndromes associadas ou alteração neurológica e uso de sonda não fizeram parte da amostra. O período de coleta dos dados foi de julho a outubro de 2008.

A coleta foi realizada no Ambulatório de Cirurgia Pediátrica do Hospital Criança Conceição (GHC), individualmente, em uma sala com o paciente e seu responsável.

Com o responsável pela criança realizou-se entrevista (Figura 1) composta por 17 perguntas referentes à alimentação, ao tipo de fissura de cada paciente, se foi amamentado exclusivamente, por quanto tempo, com que idade outros alimentos além do leite materno foram introduzidos, com que idade parou de amamentar, a alimentação atual, modo de preparo do alimento e as dificuldades de alimentação. Logo após, aplicou-se nas crianças da amostra, um protocolo de avaliação do Sistema Estomatognático (Figura 2), adaptado pelos autores da pesquisa, baseado nos protocolos sugeridos por Altmann (1997) ${ }^{2}$ e Watson, Sell e Grunwell (2005) ${ }^{3}$. Foram avaliados aspectos das estruturas; postura, mobilidade, e tonicidade dos lábios, língua, bochechas; dentição; palato duro e a mordida, por meio da observação e palpação. Também foram avaliadas as funções de sucção, de mastigação e de deglutição com alimentos padronizados (água, iogurte e bolacha), conforme adequação para a idade da criança. Os alimentos foram oferecidos pelos responsáveis, como habitualmente estavam acostumados. 
1 Data de nascimento :

2 Idade atual: meses

3 Sexo : (1) Masc. (2) Fem.

4 Tipo de fissura:

5 Cirurgias: (1) queiloplastia (2) palatoplastia

(3) ambas (4) faringoplastia

6 Uso de Sonda : (1) sim (2) não

7 Foi amamentado exclusivamente: (1) sim (2) não

8 Quanto tempo: dias

9 Com que idade introduziu outros líquidos além do LM:

10 Como? (1) mamadeira (11) ortod. (12) comum

(2) Copo (3) colher

11 Parou de amamentar? (1) sim (2) não

12 Com que idade parou de amamentar:

13 Com que idade iniciou os alimentos pastosos:

14 Alimentação atual:
(1) Seio Materno
(2) Mamadeira
(3) Papas de fruta
(4) Papas de legumes
(5) Alimentos em pedaços
(6) Alimentos sólidos
(7) Outros:

15 Preparo do alimento:

(1) liqüidificado

(2) amassado/peneirado

(3) não processado

16 Utensílios

(1) mamadeira (11) ortod. (12) comum (2) copo

(3) colher (4) outros

17 Dificuldades de alimentação:

(1) nega queixa (2) dificuldade para sugar

(3) engasgo (4) dificuldade para deglutir

(5) dificuldade para mastigar (6) refluxo nasal

Data da entrevista:

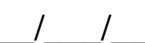

Telefone de contato:

Figura 1 - Protocolo utilizado na entrevista com os responsáveis

O presente estudo foi avaliado e aprovado pelo Comitê de Ética em Pesquisa do Hospital Nossa Senhora da Conceição - Grupo Hospitalar Conceição, sob número 088/08.

Os dados do estudo foram armazenados em um banco de dados no programa Excel. Para análise
Num pesq

Idade:

Sexo:

Tipfiss:

Cirurg:

Sonda:

Smexcl:

Tempo:

Compl:

Tipout:

meses meses

Parama:

Idpara:

Idpast:

Alimatual:

Prepalim:

Utens:

Difalim: estatística, foi usado o programa SPSS/PC 11.0., com uso de medidas de tendência central. Realizou-se análise estatística descritiva dos dados obtidos na avaliação, assim como análise teórica. Os dados são apresentados em tabelas simples e cruzadas. 


\section{AVALIAÇÃO DAS ESTRUTURAS DO SE}

\begin{tabular}{|c|c|c|}
\hline 1. Lábios & $\begin{array}{l}\text { (1) Operado } \\
\text { (2) Não operado }\end{array}$ & cirlab : \\
\hline 2. Postura de lábios & $\begin{array}{l}\text { (1) } \mathrm{c} / \text { vedamento } \\
\text { (2) } \mathrm{s} / \text { vedamento }\end{array}$ & Postlab: \\
\hline 3. Tonicidade labial & $\begin{array}{l}\text { (1) Normal } \\
\text { (2) Hipertônica } \\
\text { (3) Hipotônica }\end{array}$ & Tonlab: _ \\
\hline 4. Postura de língua & $\begin{array}{l}\text { (1) Retraída } \\
\text { (2) Protruída } \\
\text { (3) Soalho da boca } \\
\text { (4) Ponta na papila } \\
\text { (5) Não observado }\end{array}$ & Postlin: _ \\
\hline 5. Frênulo lingual & $\begin{array}{l}\text { (1) Curto } \\
\text { (2) Inserção anteriorizada } \\
\text { (3) Inserção anteriorizada e curto } \\
\text { (4) Normal } \\
\text { (5) Não observado }\end{array}$ & Frelin: __ \\
\hline 6. Tonicidade lingual & $\begin{array}{l}\text { (1) Normal } \\
\text { (2) Hipertônica } \\
\text { (3) Hipotônica }\end{array}$ & Tonlin: __ \\
\hline 7. Tonicidade de bochechas & $\begin{array}{l}\text { (1) Normais } \\
\text { (2) Hipertônicas } \\
\text { (3) Hipotônicas }\end{array}$ & Tonboc:__ \\
\hline 8. Dentição & $\begin{array}{l}\text { (1) Erupcionando } \\
\text { (2)Decídua incompleta } \\
\text { (3)Decídua completa } \\
\text { (4)Não apresenta } \\
\text { (5)Agenesia dentária } \\
\text { (6)Não observado }\end{array}$ & Dentic:__ \\
\hline 9. Palato duro & $\begin{array}{l}\text { (1) Normal } \\
\text { (2) Ogival } \\
\text { (3) Operado } \\
\text { (4) Não operado } \\
\text { (5) Fibrose } \\
\text { (6) Fístula } \\
\text { (7) Não observado } \\
\end{array}$ & Paldur: _ \\
\hline 10. Mordida & $\begin{array}{l}\text { (1) Normal } \\
\text { (2) Aberta } \\
\text { (3)Cruzada } \\
\text { (4)Não observado }\end{array}$ & Mord:__ \\
\hline
\end{tabular}




\section{AVALIAÇÃO DAS FUNÇÕES DO SE}

\begin{tabular}{|c|c|c|}
\hline 1. Sucção Nutritiva (SN) & $\begin{array}{l}\text { (1) Sim } \\
\text { (2) Não }\end{array}$ & SN : \\
\hline 2. Postura de lábios na SN & $\begin{array}{l}\text { (1) } \mathrm{c} / \text { vedamento } \\
\text { (2) s/ vedamento }\end{array}$ & Postlabn: _ \\
\hline 3. Língua na SN & $\begin{array}{l}\text { (1) Canolamento } \\
\text { (2) Protrusão } \\
\text { (3) Posteriorazição }\end{array}$ & Linsucn: __ \\
\hline $\begin{array}{l}\text { 4. Coordenação da sucção, } \\
\text { deglutição e respiração }\end{array}$ & $\begin{array}{l}\text { (1) Sim } \\
\text { (2) Não }\end{array}$ & Coorsdr:__ \\
\hline 5. Deglutição (líquidos) & $\begin{array}{l}\text { (1) Infantil } \\
\text { (2) Interposição lingual importante } \\
\text { (3) Com esforço } \\
\text { (4) Refluxo nasal } \\
\text { (5) Normal } \\
\text { (6) Não observado } \\
\end{array}$ & Degliq:__ \\
\hline 6. Deglutição (pastoso) & $\begin{array}{l}\text { (1) Infantil } \\
\text { (2) Interposição lingual importante } \\
\text { (3) Com esforço } \\
\text { (4) Refluxo nasal } \\
\text { (5) Normal } \\
\text { (6) Não observado }\end{array}$ & Degpas:__ \\
\hline 7. Deglutição (sólido) & $\begin{array}{l}\text { (1) Infantil } \\
\text { (2) Interposição lingual importante } \\
\text { (3) Com esforço } \\
\text { (4) Refluxo nasal } \\
\text { (5) Normal } \\
\text { (6) Não observado }\end{array}$ & Degsol:__ \\
\hline 8. Mastigação & $\begin{array}{l}\text { (1) Mascagem } \\
\text { (2) Mastigação unilateral } \\
\text { (3) Mastigação bilateral } \\
\text { (4) Não mastiga } \\
\text { (5) Não observado }\end{array}$ & Mastig:___ \\
\hline
\end{tabular}

Figura 2 - Protocolo de avaliação do Sistema Estomatognático

\section{RESULTADOS}

A amostra foi composta de 23 crianças de ambos os sexos, com idade entre zero e nove anos, sendo $14(60,9 \%)$ do sexo masculino e nove $(39,1 \%)$ do sexo feminino. Em relação à idade, 12 $(52,2 \%)$ casos tinham até um ano de idade, cinco $(21,7 \%)$ casos tinham entre um ano e cinco anos de idade e seis $(26,1 \%)$ casos tinham mais de cinco anos de idade. A média da idade da amostra foi de 2,76 anos e a idade variou de 12 dias a 8 anos e 4 meses.

Os tipos de fissuras encontradas foram: quatro $(17,4 \%)$ casos de fissura labial pré-forame incisivo, quatro $(17,4 \%)$ casos de fissura palatina pós-forame incisivo, nove $(39,1 \%)$ casos de fissura transforame incisivo unilateral, três $(13,0 \%)$ casos de fissura transforame incisivo bilateral e três $(13,0 \%)$ casos caracterizados como outras fissuras, incluindo dois casos de fissuras pré-forame unilateral incompleta + pós-forame incompleta e um com fissura préforame bilateral completo + úvula bífida.

Em relação às cirurgias, cinco $(21,7 \%)$ pacientes realizaram Queiloplastia, dois (8,7\%) Palatoplastia, seis $(26,1 \%)$ fizeram ambas e $10(43,5 \%)$ não tinham realizado cirurgias, ainda. Dos 23 pacientes, cinco $(21,7 \%)$ deles fizeram uso de sonda e 17 (73,9\%) não fizeram uso, apenas um (4,35\%) caso, o responsável não soube responder, porque a criança era filha adotiva. 
Sobre a amamentação, dois $(8,75 \%)$ foram amamentados exclusivamente e $20(87,0 \%)$ não. Ainda, um $(4,3 \%)$ responsável não soube responder. Dos 23 pacientes, 12 receberam amamentação complementada, sendo nove $(39,1 \%)$ casos por menos de um mês, dois $(8,7 \%)$ por um mês, um $(4,4 \%)$ amamentou por seis meses. O tempo médio de aleitamento materno exclusivo foi de 12,6 dias.

Vinte casos $(87,0 \%)$ introduziram a alimentação de diversas formas: 15 (75\%) casos com mamadeira de bico comum, dois (10\%) com mamadeira de bico ortodôntico, três (15\%) com copo, três $(15 \%)$ com colher, dois $(10 \%)$ com seringa e dois $(10 \%)$ com mamadeira especial para pacientes com fissura labiopalatal.

A Tabela 1 mostra a relação entre a amamentação exclusiva e o tipo de fissura.

Sobre a idade na qual os pacientes iniciaram a introdução dos alimentos pastosos, foi encontrado que em nove $(39,1 \%)$ casos a alimentação pastosa foi introduzida de 3 a 5 meses, oito $(34,8 \%)$ de 6 a 8 meses e seis $(26,1 \%)$ ainda não tinham introduzido por terem menos de 3 meses.

As formas de alimentação atual verificadas foram: três $(13,0 \%)$ casos alimentavam-se no seio materno, $14(60,9 \%)$ na mamadeira, seis $(26,1 \%)$ com papas de fruta, três $(13,0 \%)$ com papas de legumes, seis $(26,15 \%)$ com alimentos em pedaços e $13(56,5 \%)$ com alimentos sólidos. Verificou-se que três $(13,0 \%)$ casos liquidificavam os alimentos, sete $(30,4 \%)$ amassavam e $12(52,2 \%)$ casos consumiam os alimentos não processados.

Sobre os utensílios usados atualmente: dois $(8,7 \%)$ casos usavam mamadeira de bico ortodôntico, $15(65,2 \%)$ casos usavam mamadeira de bico comum, 13 (56,5\%) usavam copo, $17(73,9 \%)$ usavam colher e quatro $(17,4 \%)$ outros tipos de utensílios, como, por exemplo, garfo e faca. Na Tabela 2, dos 23 pacientes observa-se o uso da mamadeira conforme a idade e o tipo de bico.

As maiores dificuldades alimentares relatadas pelos responsáveis pelas crianças foram: seis $(26,1 \%)$ casos tinham dificuldade para sugar, 10 $(43,5 \%)$ casos apresentavam engasgos, quatro $(17,4 \%)$ casos tinham dificuldade para deglutir, três casos tinham dificuldade para mastigar $(13,0 \%)$ e 12 casos tinham refluxo nasal $(52,2 \%)$.

A Tabela 3 mostra a relação entre tipo de fissura e mães que negavam queixa sobre as dificuldades de alimentação dos pacientes fissurados. Observou-se que de oito pacientes que negavam queixa, quatro tinham fissura pré-forame incisivo, sendo que dois haviam feito queiloplastia; um com fissura pós-forame incisivo não havia realizado cirurgia;

Tabela 1 - Relação entre amamentação exclusiva e tipo de fissura

\begin{tabular}{|c|c|c|c|c|c|c|c|}
\hline & & \multicolumn{6}{|c|}{ Tipo de Fissuras } \\
\hline & & $\begin{array}{l}\text { Labial } \\
\text { Pré- } \\
\text { forame }\end{array}$ & $\begin{array}{l}\text { Palatina } \\
\text { Pós- } \\
\text { forame }\end{array}$ & Outros & $\begin{array}{c}\text { Transforame } \\
\text { Unilateral }\end{array}$ & $\begin{array}{c}\text { Transforame } \\
\text { Bilateral }\end{array}$ & Total \\
\hline \multirow{3}{*}{$\begin{array}{c}\text { Amamentação } \\
\text { Exclusiva }\end{array}$} & Sim & $\begin{array}{c}1 \\
25 \%\end{array}$ & - & - & - & $\begin{array}{c}1 \\
33,3 \%\end{array}$ & $\begin{array}{c}2 \\
8,7 \%\end{array}$ \\
\hline & Não & $\begin{array}{c}3 \\
75 \%\end{array}$ & $\begin{array}{c}4 \\
100 \%\end{array}$ & $\begin{array}{c}4 \\
100 \%\end{array}$ & $\begin{array}{c}8 \\
100 \%\end{array}$ & $\begin{array}{c}2 \\
66,7 \%\end{array}$ & $\begin{array}{c}20 \\
87 \%\end{array}$ \\
\hline & $\begin{array}{l}\text { Não } \\
\text { sabe }\end{array}$ & - & - & - & $\begin{array}{c}1 \\
11 \%\end{array}$ & - & $\begin{array}{c}1 \\
4,3 \%\end{array}$ \\
\hline \multicolumn{2}{|l|}{ Total } & $\begin{array}{c}4 \\
100 \%\end{array}$ & $\begin{array}{c}4 \\
100 \%\end{array}$ & $\begin{array}{c}3 \\
100 \%\end{array}$ & $\begin{array}{c}9 \\
100 \%\end{array}$ & $\begin{array}{c}3 \\
100 \%\end{array}$ & $\begin{array}{c}23 \\
100 \%\end{array}$ \\
\hline
\end{tabular}

Tabela 2 - Relação entre a idade e o tipo de bico de mamadeira utilizado

\begin{tabular}{cccccc}
\hline \multirow{2}{*}{ IDADE (anos) } & \multicolumn{4}{c}{ MAMADEIRA } \\
\cline { 2 - 5 } & \multicolumn{3}{c}{ Bico comum } & \multicolumn{2}{c}{ Bico ortodôntico } \\
\cline { 2 - 5 } & $\mathrm{n}$ & $\%$ & 2 & $\%$ \\
\hline 0 a 1 & 8 & 34,78 & 0 & 0 \\
1.1 a 5 & 5 & 21,73 & 0 & 0 \\
Mais de 5 & 2 & 8,7 & 0,7 \\
\hline
\end{tabular}


Tabela 3 - Relação entre tipo de fissura e mães que negavam queixa sobre as dificuldades de alimentação dos pacientes fissurados

\begin{tabular}{cccccccc}
\hline & & \multicolumn{7}{c}{ Tipo de Fissuras } & & \\
\cline { 3 - 7 } & & $\begin{array}{c}\text { Labial } \\
\text { Pré- } \\
\text { forame }\end{array}$ & $\begin{array}{c}\text { Palatina } \\
\text { Pós- } \\
\text { forame }\end{array}$ & Outros & $\begin{array}{c}\text { Transforame } \\
\text { Unilateral }\end{array}$ & $\begin{array}{c}\text { Transforame } \\
\text { Bilateral }\end{array}$ & Total \\
\hline Nega & Não & & 3 & 3 & 6 & 3 & 15 \\
queixa & Sim & 4 & $75 \%$ & $100 \%$ & $66,7 \%$ & $100 \%$ & $65,2 \%$ \\
& $100 \%$ & $25 \%$ & - & 3 & $33,3 \%$ & - & 8 \\
Total & 4 & 4 & 3 & 9 & 3 & 23 \\
\hline & $100 \%$ & $100 \%$ & $100 \%$ & $100 \%$ & $100 \%$ & $100 \%$ \\
\hline
\end{tabular}

três com fissura transforame unilateral; desses três casos, dois realizaram queiloplastia e palatoplastia.

$\mathrm{Na}$ Tabela 4, mostra-se a distribuição das alterações das estruturas do Sistema Estomatognático. Observou-se que, dentre as alterações mais frequentes, $13(56,5 \%)$ pacientes apresentavam postura de lábios sem vedamento, $18(78,3 \%)$ língua no soalho da boca, dois $(8,7 \%)$ frênulo lingual curto com inserção anteriorizada, sete $(30,4 \%)$ bochechas hipotônicas, oito $(34,8 \%)$ palato duro não operado e cinco $(21,7 \%)$ mordida cruzada.

Quanto à avaliação das funções do Sistema Estomatognático, quatro casos (17,4\%) tinham postura de lábios na sucção nutritiva sem vedamento, três casos (13,0\%) não apresentaram coordenação da sucção, deglutição e respiração.

A Tabela 5 mostra a distribuição das alterações das funções do Sistema Estomatognático. $\mathrm{Na}$ deglutição de líquidos, observou-se quatro $(17,4 \%)$ com interposição lingual importante. Com alimento pastoso, verificaram-se dois $(8,7 \%)$ casos com interposição lingual importante e dois $(8,7 \%)$ casos que apresentaram outras alterações, como, por exemplo: tosse e escape de alimento. Na deglutição com sólidos, constataram-se cinco $(21,7 \%)$ com esforço. A mascagem observou-se como alteração em 11 $(47,8 \%)$ pacientes, sendo bastante frequente.

\section{DISCUSSÃO}

Na presente pesquisa, houve um número maior de crianças do sexo masculino, o que concorda com os dados da literatura, nos quais a fissura labiopalatina afeta mais indivíduos desse sexo ${ }^{6,7}$.

O tipo de fissura mais encontrado foi transforame incisivo unilateral, o que é confirmado em vários estudos, como o de maior frequência ${ }^{8-12}$.

As crianças com fissuras labiopalatinas nascidas a termo e sem nenhuma intercorrência
Tabela 4 - Distribuição conforme as alterações das estruturas do Sistema Estomatognático

\begin{tabular}{lcc}
\hline Itens Avaliados & N & $\%$ \\
\hline Postura de lábios sem & 13 & 56,5 \\
vedamento & 12 & 52,2 \\
Lábios não operados & 11 & 47,8 \\
Lábios operados & 4 & 17,4 \\
Lábios Hipotônicos & 2 & 8,7 \\
\hline Lábios Hipertônicos & 23 & 100,0 \\
\hline Total avaliados & 18 & 78,3 \\
\hline Língua Soalho da boca & 2 & 8,7 \\
Língua Retraída & 1 & 4,3 \\
Língua Protruída & 1 & 4,3 \\
Língua ponta na papila & 1 & 4,3 \\
\hline Língua Hipertônica & 22 & 100,0 \\
\hline Total avaliados & 2 & 8,7 \\
\hline Frênulo Lingual Inserção & 1 & 4,3 \\
anteriorizada e curto & 1 & 4,3 \\
Frênulo Lingual Curto & 15 & 100,0 \\
\hline Frênulo Lingual Inserção & 7 & 30,4 \\
\hline anteriorizada & 23 & 100,0 \\
\hline Total avaliados & 3 & 13,0 \\
\hline Bochechas Hipotônicas & 23 & 100,0 \\
\hline Total avaliados & 8 & 34,8 \\
\hline Agenesia dentaria & 6 & 26,1 \\
\hline Total avaliados & 4 & 17,4 \\
\hline Palato duro não operado & 3 & 13,6 \\
\hline Palato duro ogival & 20 & 100,0 \\
\hline Palato duro com fibrose & 5 & 21,7 \\
Palato duro com Fístula & 1 & 8,7 \\
\hline Total avaliados & 23 & 100,0 \\
\hline Mordida Cruzada & & \\
Mordida Aberta & 1,3 \\
Outras alterações de mordida & & \\
Total avaliados & 1 & \\
\hline & & \\
\end{tabular}


Tabela 5 - Distribuição das alterações das funções do Sistema Estomatognático

\begin{tabular}{lcc}
\hline Deglutição de líquidos & $\mathrm{N}$ & $\%$ \\
\hline Infantil & 1 & 4,3 \\
Interposição lingual importante & 4 & 17,4 \\
Com esforço & 0 & 0,0 \\
Refluxo nasal & 0 & 0,0 \\
Não observado & 0 & 0,0 \\
Outros & 3 & 13,0 \\
\hline Total avaliados & 13 & 100,0 \\
\hline Deglutição de pastoso & & \\
Infantil & 0 & 0,0 \\
Interposição lingual importante & 2 & 8,7 \\
Com esforço & 1 & 4,3 \\
Refluxo nasal & 1 & 4,3 \\
Não observado & 0 & 0,0 \\
Outros & 2 & 8,7 \\
\hline Total avaliados & 16 & 100,0 \\
\hline Deglutição de sólidos & & \\
Infantil & 1 & 4,3 \\
Interposição lingual importante & 3 & 13,0 \\
Com esforço & 5 & 21,7 \\
Refluxo nasal & 0 & 0,0 \\
Não observado & 0 & 0,0 \\
\hline Total avaliados & 14 & 100,0 \\
\hline Mastigação & 11 & 47,8 \\
Mascagem & 1 & 4,3 \\
Mastigação unilateral & 1 & 4,3 \\
Mastigação bilateral & 43,5 \\
\hline Não se aplica & 100,0 \\
\hline Total avaliados & & \\
\hline & & \\
& 14 & \\
\hline
\end{tabular}

associada podem, normalmente, ser alimentadas desde o nascimento, não necessitando do uso de sondas nasogástricas. Observou-se, no presente estudo, que houve um número maior de crianças que não fizeram uso de sonda para alimentar-se, concordando com as afirmações dos autores ${ }^{2,3,5}$.

Apenas dois pacientes, neste estudo, foram amamentados exclusivamente. Embora, o ideal seja que o aleitamento materno realize-se pelo tempo mais longo possível devido a benefícios comprovados, como as qualidades imunológicas que protegem contra a otite média recorrente e outras infecções $^{2,3}$, parte das mães dessas crianças não recebem orientações sobre amamentação enquanto estão no hospital ${ }^{10-13}$, o que pode ter influenciado na baixa ocorrência dessa prática na amostra.

Desses dois pacientes que foram amamentados exclusivamente, um era portador de fissura préforame incisivo. Em alguns estudos, foi encontrado que a variação no desempenho de sucção está de acordo com a condição do tipo de fissura do bebê. Bebês com palato intacto ou palato amplamente intacto (aqueles com fissura labial ou fissura secundária de palato mole) apresentaram níveis de sucção semelhante com bebês com sucção saudáveis; porém, os bebês com fissura palatina mais extensa ou fissura labiopalatina não apresentam níveis normais de sucção ${ }^{9,11,12}$. Também foi encontrado um caso de fissura transforame bilateral que foi amamentado exclusivamente, o que difere das afirmações anteriores. Já outros autores ${ }^{2}$ constataram que nem toda a dificuldade de sucção corresponde ao grau das estruturas, como extensão e largura da fissura. Fatores, como informação sobre técnicas corretas de amamentação e suporte profissional para as mães, podem ajudar no estabelecimento do aleitamento natural ${ }^{2,12}$.

A respeito da introdução dos alimentos mais consistentes, o presente estudo mostrou, de modo geral, uma introdução precoce de pastosos, entre 3 e 5 meses. Geralmente, recomenda-se que as crianças com fissuras labiopalatinas não recebam alimentos pastosos antes dos cinco meses, e a partir dos seis meses deve-se oferecer uma dieta mista ${ }^{2,11}$. Já com respeito à dieta atual, quando os dados foram cruzados com a idade, a alimentação na sua consistência estava adequada, entre os pacientes pesquisados, uma vez que os alimentos consumidos, na sua maioria, eram amassados ou em pedaços, concordando com achados de outros autores ${ }^{13}$.

Dos 23 pacientes, dois $(8,7 \%)$ usavam mamadeira com bico ortodôntico e tinham até um ano de idade, o que está de acordo com autores que afirmam que os bicos de mamadeira mais adequados são os ortodônticos, por serem curtos e anatômicos. $\mathrm{O}$ furo deve ser graduado de acordo com o poder de sucção que cada criança tem, sendo um tamanho regular, indicado para intensificar o movimento de sucção. O bico é posicionado para parte anterior da boca e com o furo voltado para cima, evitando engasgos ${ }^{2,12}$, ao contrário do que se encontra entre os pacientes que usam mamadeira de bico comum, pois, dos 23 pacientes, 15 (65,2\%) usavam bico comum, em idades superiores aos dois anos, inclusive dois $(33,3 \%)$ com mais de 5 anos. A retirada da mamadeira deve acontecer entre um ano e seis meses e dois anos de idade para que não ocorram problemas dentários e musculares, ainda mais em pacientes com sérias alterações como os fissurados ${ }^{2,12}$.

Conforme a literatura, as dificuldades mais encontradas na alimentação de crianças com fenda de lábio e /ou palato são causadas pela sucção ineficiente e a regurgitação do leite para a cavidade nasal, o que concorda com os achados desta 
pesquisa, nos quais foram encontrados maiores queixas de refluxo nasal, dificuldade de sucção e engasgos ${ }^{2,3,12}$.

Crianças com fissura labial ou fissura secundária de palato mole apresentam níveis de sucção parecidos com crianças saudáveis ${ }^{2,3}$. Esta afirmação está de acordo com os achados do atual estudo, no qual crianças que não apresentaram queixas de dificuldade de alimentação, na sua maioria, apresentavam fissura pré-forame incisivo, ou seja, labial ${ }^{3,9}$. Porém, as mães que negaram queixa em pacientes com fissura transforame unilateral apresentavam alterações na avaliação fonoaudiológica. Isso pode ocorrer pela falta de informação que as mães têm sobre a diferença entre o normal e o alterado; fatores como desconhecimento, escolaridade e nível sócio-econômico baixos podem interferir nesses casos ${ }^{3,14}$.

Em relação a alterações das estruturas do sistema estomatognático, foram encontradas alterações de tonicidade, postura inadequada de lábios, língua e bochechas, mordida alterada, principalmente, mordida cruzada e agenesias dentárias, concordando com um estudo que investigava essas estruturas e achou resultados semelhantes ${ }^{7}$.

Nas alterações das funções do sistema estomatognático, verificou-se que os pesquisados apresentavam interposição lingual importante na deglutição para as consistências pastosas, líquidas e sólidas, o que é confirmado na literatura como um achado frequente, pois nos fissurados pré-forame ou transforame, praticamente todos os indivíduos apresentam deglutição adaptada ou atípica, ou seja, a língua projeta-se entre as arcadas dentárias, evitando o vedamento labial, tocando o vestíbulo labial ou exercendo uma pressão anterior sobre a superfície interna dos dentes ${ }^{2,3}$.

A mastigação cumpre importantes funções ao ser realizada com igual intensidade, durante um mesmo tempo, alternando-se os lados, estimulando o desenvolvimento simétrico da região maxilofacial ${ }^{2,3}$. No presente estudo, a mascagem foi encontrada em um grande número dos pacientes estudados, como alteração, ou seja, em crianças que pela idade já deveriam apresentar mastigação adequada. Por isso, é importante, na avaliação, observar se a mastigação é bilateral ou unilateral e se existem movimentos rotatórios, levando em conta que os pacientes fissurados, por apresentarem problemas oclusais e dentários, tendem a ter mais alterações dessa função ${ }^{2,3}$.

\section{CONCLUSÃO}

A fissura transforame, mesmo sendo mais complexa, não excluiu o aleitamento materno exclusivo; porém, é mais difícil de acontecer.

Constatou-se que houve introdução de alimentação pastosa entre 3 e 5 meses, considerada precoce.

O uso da mamadeira com bico comum, acima dos 36 meses, apresentou-se como hábito deletério mais frequente.

As maiores dificuldades na alimentação das crianças com fenda de lábio e /ou palato relatadas pelas mães foram engasgos, refluxo nasal e dificuldade de sugar.

As alterações das funções do sistema estomatognático mais frequentes encontradas foram interposição lingual importante na deglutição e mastigação do tipo mascagem.

A atual pesquisa apresenta limitações de número amostral, portanto, são sugeridas mais pesquisas sobre as alterações de alimentação em indivíduos com fissura labiopalatina sobre o padrão de mastigação e deglutição, principalmente com crianças acima de 3 anos de idade, faixa na qual os estudos científicos são escassos.

\section{AGRADECIMENTOS}

Agradecemos ao Dr. Paulo Sérgio Gonçalves da Silva e à equipe do Hospital da Criança Conceição, já que sem sua disponibilidade e colaboração, não teria sido possível esta pesquisa. 


\begin{abstract}
Purpose: to evaluate feeding in children with cleft lip and/or palate and describe their characteristics; to check the sort of feeding and their feeding difficulties. Methods: we used a quantitative, crosssectional, observational and descriptive study. Twenty-three cleft patients from 0 to 9-year old were evaluated in this study. Interviews were accomplished with the sponsors. We carried out a descriptive statistical analysis of the data obtained in the evaluation, as well as the theoretical analysis. Results: the most found sort of cleft was the Unilateral Transforame Cleft. From the 23 children, two (8.75\%) were exclusively breastfeeding. Major feeding difficulties were: six (26.1\%) difficulty to suck, 10 (43.5\%) choking, four (17.4\%) difficulty to swallow, three (13.0\%) difficulty to chew and $12(52.2 \%)$ had nasal reflux. The more frequent alterations of the Stomatognathic System were found in the swallowing important lingual interference and mastication of chewing type. Conclusion: the transforame cleft, even being more complex, did not exclude the exclusive breastfeeding; the sort of feeding related with the patients' age, presents itself in an appropriate way; part of the patients still use the bottle with a common nipple, constituting a harmful habit. Major difficulties in feeding reported by mothers were choking, nasal reflux and sucking difficulty. The children that did not have complaints of feeding difficulty were the ones with incisive preforame cleft.
\end{abstract}

KEYWORDS: Cleft Lip; Cleft Palate; Feeding Methods; Eating Disorders

\section{REFERÊNCIAS}

1. García AR, Peña BC, Marín E, Felzani $R$, Morales O. Diagnóstico prenatal de las hendiduras labiopalatinas. Acta Odonto Venez. 2006 Abr; 44(3):399-405.

2. Altmann EBC. Fissuras Labiopalatinas. 4. ed. Carapicuíba: Pró-Fono; 1997.

3. Watson ACH, Sell DA, Grunwell P. Tratamento de fissura labial e fenda palatina. São Paulo: Santos; 2005.

4. Centro de Atendimento Integral ao Fissurado Lábio-palatal-CAIF. Secretaria do Estado de Saúde. [homepage na internet] Paraná. [acesso em 20 abr 2008] Disponível em: URL: http://200.189.113.52/ caif/fissura_2.htm

5. Araruna RC, Vendrúscolo DMS. Alimentação da criança com fissura de lábio e/ou palato: um estudo bibliográfico. Rev Latino-Am Enferm. 2000 abr; 8(2):99-105.

6. Nunes LMN, Queluz DP, Pereira AC. Prevalência de fissuras labiopalatais no município de Campos dos Goytacazes-RJ, 1999-2004. Rev Bras Epidemiol. 2007 mar; 10(1):109-16.

RECEBIDO EM: 29/01/2009

ACEITO EM: 20/09/2009

Endereço para correspondência:

Susana Elena Delgado

Rua Pedro Chaves Barcelos, 892/201

Porto Alegre - RS

CEP: $90450-010$

E-mail: sudel.ez@terra.com.br
7. Silva RN, Santos EMNG. Ocorrência de alterações da motricidade oral e fala em indivíduos portadores de fissuras labiopalatinas. Rev Bras Promoção Saúde. 2004; 17(1):27-30.

8. Montagnoli LC, Barbieri MA, Bettiol H, Marques IL, Souza L. Prejuízo no crescimento de crianças com diferentes tipos de fissura lábio-palatina nos 2 primeiros anos de idade: um estudo transversal. J Pediatr. 2005; 81(6):461-5.

9. Reid J, Reilly S, Kilpatrick N. Sucking performance of babies with cleft conditions. Cleft Palate Craniofac J. 2007; 44(3):312-20.

10. Pini JG, Peres SPBA. Alimentação do lactente portador de lesão lábio-palatal: aleitamento e introdução alimentar. Rev Nutr. 2001 set-dez; 14(3):195-9.

11. Silva EBD, Fúria CLB, Di Ninno CQDMS. Aleitamento materno em recém-nascidos portadores de fissura labiopalatina: dificuldades e métodos utilizados. Rev. CEFAC. 2005 jan-mar; 7(1):21-8.

12. Mendes LGA, Lopes VLGS. Fenda de lábio e ou palato: recursos para alimentação antes da correção cirúrgica. Rev Ciênc Méd. 2006 set-out; 15(5):437-48.

13. Di Ninno CQMS, Gomes RDO, Moura DFD, Costa BLMD. Informações que os pais de bebês com fissura labiopalatina gostariam de receber no período neonatal. Rev Soc Bras Fonoaudiol. 2006; 11(1):10-6.

14. Mendes LGA, Magna LA, Lopes VLGDS. Neonatal care of infants with cleft lip and/or palate: feeding orientation and evolution of weight gain in a nonspecialized Brazilian hospital. Cleft Palate Craniofac J. 2007 may; 44(3):329-34. 